\title{
Epicurus on the false belief that sense-impressions conflict
}

James Warren

\section{(2) OpenEdition}

1 Journals

Electronic version

URL: https://journals.openedition.org/philosant/3019

DOI: $10.4000 /$ philosant.3019

ISSN: 2648-2789

\section{Publisher}

Éditions Vrin

\section{Printed version}

Date of publication: 31 October 2019

Number of pages: 7-28

ISBN: 978-2-7574-2534-3

ISSN: 1634-4561

\section{Electronic reference}

James Warren, "Epicurus on the false belief that sense-impressions conflict", Philosophie antique [Online], 19 | 2019, Online since 01 October 2020, connection on 02 December 2022. URL: http:// journals.openedition.org/philosant/3019; DOI: https://doi.org/10.4000/philosant.3019

\section{(c) $(7)(9$}

Creative Commons - Attribution-NonCommercial-NoDerivatives 4.0 International - CC BY-NC-ND 4.0 https://creativecommons.org/licenses/by-nc-nd/4.0/ 


\section{EPICURUS ON THE FALSE BELIEF THAT SENSE-IMPRESSIONS CONFLICT}

James WARREN

Corpus Christi College, Cambridge

RÉSUMÉ. Selon les épicuriens, toutes les impressions des sens sont vraies et la raison trouve en elles son fondement. Nombreux sont ceux, cependant, qui croient que les impressions des sens ne sont pas toutes vraies. Les épicuriens expliquent cette croyance de la façon suivante : la source de cette erreur est souvent la croyance que les impressions des sens peuvent se contredire. Mais cette dernière croyance résulte souvent de ce que les épicuriens tiennent pour notre tendance naturelle, et fréquemment utile, à généraliser et à former des opinions par extrapolation à partir des impressions de nos sens.

SUMMARY. Epicureans say that all sense-impressions are true and that reason is based on sense-impressions. But lots of people believe that not all sense-impressions are true. The Epicureans explain why people might hold this false belief as follows: the belief at the root of such mistakes is often the belief that sense-impressions can conflict. But this latter belief is often the result of what the Epicureans think is our natural and often helpful tendency to generalise and extrapolate in forming beliefs on the basis of our sense-impressions.

Philosophie antique, $\mathrm{n}^{\circ} 19$ (2019), 7-28 

Epicurus says that all sense-impressions are true and that all of our general concepts are based on these sense-impressions. ${ }^{1}$ But some people believe that some sense-impressions are false. More worryingly, some people even go on to base various wild epistemological and metaphysical theories on the conviction that not all sense-impressions are true. My question for the Epicureans, therefore, is: Why would anyone ever come to form such a belief and do so, what is more, on the basis of true perceptions on which-so the Epicureans say-all reason depends (Diogenes Laertius, 10.32)? Although I will concentrate on this particular question about the formation of false beliefs about perceptions on the basis of true perceptions, there is also a similar question in the case of values which I will not pursue here, namely: the Epicureans are clear that we all are equipped with the ability to detect unerringly what is good and what is bad since the pathe of pleasure and pain are criteria of truth. The question arises: why is it that anyone should ever come to think that some pleasures are bad or that something other than pleasure is good? Again, there must be some explanation that accounts for such errors given that the Epicureans insist that our basic apparatus both for perceiving how things are and also for perceiving what is good and bad is always truth-telling. ${ }^{2}$

* An early version of this paper was presented in Cambridge to the 2016 BPPA Masterclass: Perception and Perceptual Appearances in Ancient Philosophy. I would like to thank all the participants for their comments and, in particular, Cristóbal Zarzar for organising the conference and inviting me to speak. It also benefited from helpful comments from Thomas Bénatouil and the journal's referee.

1. For further discussion of that thesis see: Striker 1977, Taylor 1980, Scott 1989, and Everson 1990.

2. I am also not concerned here with the interesting but complicated question of the precise history of the Epicureans' various encounters with and reactions to different kinds of scepticism or in deciding whether Lucretius engages with Aenesidemus, and so on. For discussion of such questions see, for example, Gigante 1981, Schrijvers 1992, and Lévy 1997. I shall also for the most part set aside the task of evaluating whether the Epicureans can 
One way to diagnose the error that generates these unfortunate mistakes is to look for reasons why people might come to think, for example, that a given sense-impression may be false. Most commonly, arguments that attempt to show this are based on cases of purported perceptual conflict. ${ }^{3}$ If there are two sense-impressions that are in conflict then, of course, it cannot be the case that both of them are true. There is no need to determine which of the conflicting sense-impressions is not true because the conflict alone is sufficient to show that at least one of them must be. So we can imagine that occasionally people come to hold the false opinion that the two members of a pair of sense-impressions are in conflict and that therefore at least one of the impressions must be false. This is sufficient to show that not all our sense-impressions can be relied upon. Various forms of what we might label scepticism but ancient sceptics like the Pyrrhonists and Academics might think of as a form of 'negative dogmatism' may then emerge from the conviction that our senses cannot be relied upon for truths about the world around us. Perhaps all of them are false. Or perhaps some of them are true but it is impossible to ascertain which of them are true and which are false. Either way, these thinkers will begin with an initial conviction that sense-impressions may be in conflict with one another and end with a generally negative assessment of our senses as useful sources of truths about the world. When they go on to form these disastrous general metaphysical and epistemological views and even-heaven forbid-become sceptics of some kind or other, therefore, it may often be in part because of their being convinced of the possibility of such conflicts.

Then we might ask: why would anyone ever come to have the opinion that there are cases of perceptual conflict of this kind? The problem of conflicting appearances cannot even begin, we might say, unless it is plausible that there might be such conflicts. Perhaps more precisely, the problem of conflicting appearances can begin only if it seems reasonable ever to hold the opinion that two sense-impressions are in fact in conflict. But why would anyone think that $?^{4}$ I hope that this does not seem to be an overly simple-minded question. I am not sure, for example, whether we can reasonably assert that it is simply a natural tendency of some kind that we should come to the view that there are cases of perceptual conflict of the relevant kind. Perhaps we

successfully resist a variety of sceptical doubts about the truth of our sense-impressions, aside from asking whether they can offer a diagnosis according to their own epistemological and psychological commitments of this particular fashion in which sceptical positions may arise based on the false conviction that sense-impressions may conflict with one another.

3. See Burnyeat 1981 for an account of the various reactions to purported cases of conflicting appearances, both perceptual appearances and the other forms of appearance.

4. Burnyeat 1981, p. 73, asks: 'Why have some philosophers been so impressed, while others like Austin remain unimpressed, by the familiar fact that appearances conflict?' (my emphasis). 
think about such things only when prompted to do so by a mischievous philosopher. But in any case I think this is a question that might repay at least a small amount of attention and it is surely a question that the Epicureans should have considered.

I am asking what the Epicurean account will be of the reasons why people often adopt a certain kind of false opinion. In fact, I want to ask about two kinds of false opinion. The first is a false opinion about a particular pair of appearances: the opinion 'that sense impression $A$ and sense impression $B$ are in conflict'. The second is a false opinion about appearances in general: the opinion 'that senses impressions may be in conflict with one another.' The two kinds of opinion will often accompany one another since the former kind will license the latter, general, kind. And the latter general opinion may well incline a person to form a belief of the former kind about a given pair of appearances. I take it to be the case, all the same, for the Epicureans that both opinions are false. It is false for any pair of sense-impressions that those sense-impressions are in conflict because all sense-impressions are true.

It is worthwhile asking the Epicureans why they think people form these false opinions about the possibility of conflicting appearances because the Epicureans do, as is well known, have various things to say that appear to be aimed at answering or criticising different kinds of sceptical outlook. So they ought to have some view about how to diagnose the tendency to adopt these misguided sceptical positions. And it is certainly the case that conflicts of appearances are prime pieces of evidence or prime starting points for various kinds of sceptical thought, ranging from the positions of Melissus and Democritus through to Plato and then to Sextus Empiricus' modes for generating diaphonia. (Sextus, of course, is careful to point out that it merely appears to him that appearances and opinions conflict; he is not committed to the belief that they do in fact so conflict.) So it is a good idea for the Epicureans to be able to say something not just about why scepticism is not justified but also about why someone might be misled into forming such a view. They do, after all, have quite a lot to say about how we tend to form beliefs about topics such as what is of value and how those opinions are often mistaken. And yet there is not very much explicit Epicurean discussion of this specific question about the opinion that sense-impressions conflict.

We do, however, have a brief account from Sextus Empiricus in $M .7$ of an Epicurean discussion of this kind of mistake. Sextus has just spent three paragraphs outlining the Epicurean account of both pathe and phantasiai. In the case of the latter, he explains, the Epicureans insist that they are all true (aletheis) not only in the sense that a visible object, for example, appears visibly but also in the sense that the visual object is qualitatively as it appears 


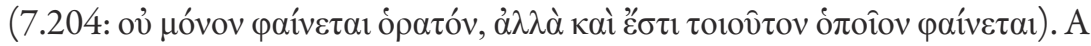
little later he turns to address the question why some people are nevertheless mistaken about the truth of these appearances.

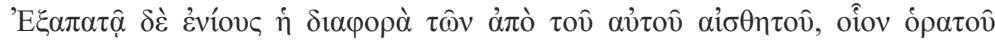

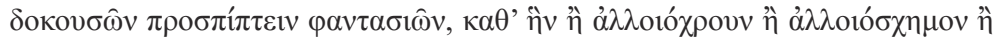

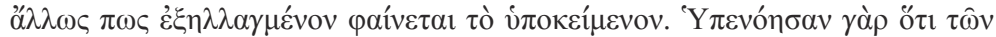

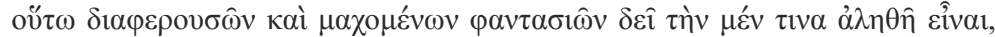

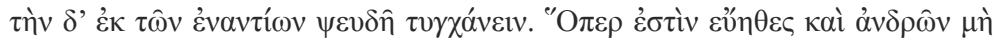

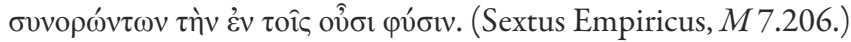

However, what fools some people is the difference in the appearances that seem to strike us from the same perceptible (e.g. visible) thing, in virtue of which the existing thing appears to be another colour or another shape or in some other way changed. For they supposed that, of the appearances that thus differ and compete, one of them must be true, while the other one of opposite origins turns out to be false. But that is silly, and typical of men who fail to see the nature in things. (Trans. Bett 2005, with modifications.)

Here we have a description of how some people are deceived and therefore form a false opinion about either the possibility of conflicting sense-impressions in general or some particular purported case of such conflict. ${ }^{5}$ The inspiration comes from the familiar thought that one and the same percep-

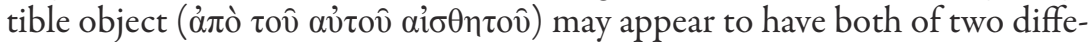
rent perceptual properties at a single time or might otherwise appear differently from one time to another. The assumption, we may presume, is that the visible object itself cannot be both of these colours or shapes and therefore

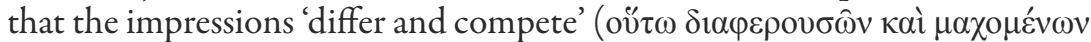
$\varphi \alpha \nu \tau \alpha \sigma \iota \hat{\omega} \nu)$. The implication is either that the visible object cannot be both of these colours or shapes at any given single time but it appears to be so or else that it appears one colour at one time and another colour at another time but there is no reason to think that it has in fact changed in a relevant way in the intervening period. So these perceptions cannot all be true. But, according to the Epicureans, they are all true.

The important distinction we will need to make is between (i) two sense-impressions differing and (ii) two sense-impressions being in conflict with one another. These are elided in Sextus' report of what the subject of these impressions thinks about the situation ( and this is an instructive elision; the Epicureans will insist that although impressions may differ, they cannot conflict because they are all true. And therefore we need to be careful when setting out precisely what the Epicureans

5. For the source of this section of Sextus' account see Sedley 1992. It is likely that Sextus or his source is using original Epicurean terminology and that therefore some of this account may derive directly from an Epicurean text. Consider in particular the use of the participle

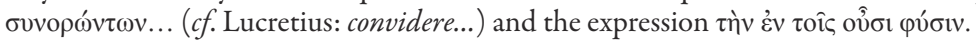


claim according to this report. For example, when these people are said to be deceived by the difference in the appearances this must be interpreted carefully. The perceptions themselves, of course, are famously non-rational (alogoi) and are all true. And therefore the perceptions themselves, far from being able to deceive anyone, consistently and without fail are reliable sources of information. They are criteria of truth. So the emphasis must fall on the notion of 'difference' here and, if any deception is happening, then it must be as a result of some cognitive work done by the perceiver in addition to the simple receipt of differing perceptual appearances. The sense of 'being deceived' which is intended, therefore, is really a sense in which the perceiving agent himself makes some kind of mistake in the way the truthtelling appearances are being understood. Sextus might be happy to say that there is some kind of second-order appearance: the appearance that these appearances are in conflict. It is most likely that Epicurus himself would have characterised this as a belief: the belief that the appearances conflict or a belief that some appearance is false. And the Epicureans will also say that this belief is deceptive and actively prevents the perceiver from recognising the true sense-impressions for what they are.

Let us now turn to the crucial second sentence in this quotation: "For they supposed that, of the appearances that thus differ and compete..." etc. The Epicureans themselves cannot really think that the appearances do indeed

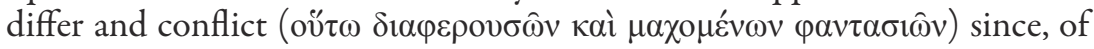
course, all these appearances are true and are therefore consistent with one another. Rather, if this is a report that the Epicureans can endorse then it must all be governed by i $\pi \varepsilon v o ́ \eta \sigma \alpha v$. The Epicureans can of course endorse the claim that things seem to certain misguided people to present conflicting appearances. However, they will insist that this is in fact a belief that such people have formed. These people-the 'some people' said to be deceived in the first sentence-have supposed that these appearances not only differ but also are in mutual conflict and that therefore at least one must be false. We should be precise about the content of the belief that seems to be operating as the source of the deception here. If the belief is simply: "These appearances differ" then that may well be true. In fact, it is very likely that it is true since, as the Epicureans themselves will also remind us, our perceptual appearances are to a large extent affected by the particular circumstances of the perceptual object, the state of the perceiver, the relation between them, their being at a particular time and place and so on. It will in that case be rather difficult to find a pair of appearances that do not differ in at least some fashion or other. But if the belief is "These appearances conflict" then of course that belief is false. It is perhaps hard to think that such a false belief is the cause of the deception since it seems instead to be the result of being deceived somehow; as a result of some kind of deception we come to hold the false view that these 
appearances conflict. And it is reasonable to think that once an agent has the belief that these appearances conflict then we can see how that agent might begin mistakenly to discard true appearances, thinking that they cannot be true, or might develop a sceptical outlook with regard to his sense-impressions. However, in that case we are still left with no explanation yet of why the false belief itself has been adopted other than the suspicion that it is in all likelihood rooted in a misunderstanding of the way in which appearances from one and the same object may differ from one another.

Sextus' brief report says little about this but perhaps we should somehow imagine that people can be deceived in the following way. They somehow acquire the belief "These appearances differ" and are misled by that (likely true) belief also to form the false belief "These appearances conflict". From that false belief, of course, all manner of unfortunate things might follow. People thus deceived might find themselves sadly tempted by the notion that there are intelligible perfect Forms of things or they might lapse into one or other version of relativism. Facilis descensus Averno. Nevertheless, this slip from the acceptable and true belief that the appearances differ to the unacceptable and false belief that the appearances conflict with one another is, I think, what the Epicureans should try to explain. Sextus' report, with a bit of unpacking, suggests that this is their best description of what happens but it falls short of providing a satisfying explanation of what happens.

The most important distinction, therefore, to draw from this passage is the distinction between differing appearances and conflicting appearances. The distinction, to put it succinctly, is as follows: appearances $\Phi 1$ and $\Phi 2$ will conflict if it cannot be the case that the content of both $\Phi 1$ and also $\Phi 2$ is true; they will differ just if the content of $\Phi 1$ and the content of $\Phi 2$ are not identical. (So: all appearances that conflict with each other also differ from one another but not all appearances that differ from one another conflict with one another.) In this brief report, the way in which these people are deceived is shown by the way in which those two notions are run together and it is this conflation of two very importantly different relationships that causes all the trouble. The Epicureans will certainly allow that senseimpressions may differ: the first sentence in Sextus' report happily talks of a diaphora between the impressions from a given visual object; that object appears to be a certain colour at one time and another colour at another. Of course the Epicureans will allow that sense-impressions caused by the same object may differ, that sense-impressions received by the same perceiver may differ, and so on. The differences can be as wide and as widespread as we like. What the Epicureans will not allow, however, is that the sense-impressions conflict with one another since they hold that all sense-impressions are true. As Sextus puts it, this difference (diaphora) between perceptions sometimes deceives people, and causes them to form the false belief that not only do the 
impressions differ but that there is also a conflict between them. What these people fail to grasp, we might say, is the difference between mere difference and conflict.

Why is there this tendency to form the false belief that a given pair of differing sense-impressions conflict or, more generally, that there are cases of perceptual conflict such that not all sense-impressions can be true? And how can it be that the otherwise acceptable (indeed, as we shall see, expected) diaphora between impressions may itself be said to be the source of this confusion? It is hard to be sure about this since there is not a great deal of explicit textual evidence to help. But my suggestion, to put it in its briefest terms, is that according to the Epicureans we humans tend to form such a false belief in part because of our otherwise often very helpful and natural tendency to extrapolate from an impression or group of impressions and form opinions that are more general than the perceptual evidence strictly warrants. This is the very tendency that allows us to form general opinions and concepts and at least sometimes it succeeds in generating things that are themselves criteria of truth, namely the prolepseis. But this same tendency, we might say, sometimes over-reaches the warrant of the perceptual input provided and causes us to form false opinions. And sometimes this results in our forming the false opinion that two impressions conflict, when in fact they do not, in part because we have also mistaken beliefs about the nature of the perceptual object of the impressions themselves. The remainder of what I have to say is aimed at fleshing out this suggestion.

Part of Diogenes Laertius' report of Epicurean psychological doctrine (10.31-32) may give an outline account of the mechanism concerned. In what seems to be an extremely compressed summary of the content of Epicurus' Kanon we are told first that perception is non rational (alogos) and does not involve memory and then that there is nothing that can refute perception because (i) a similar perception cannot refute a similar perception and (ii) a dissimilar perception cannot refute a dissimilar one. What this amounts to, it seems, is that one visual appearance cannot refute another visual appearance since there is no more reason to prefer one than the other, and no visual appearance, for example, can refute an auditory appearance since their respective objects are not the same. Just a little later, Diogenes adds the following:

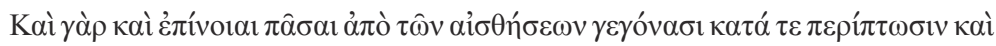

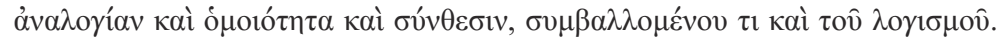
(Diogenes Laertius, 10.32.)

For all thoughts (epinoiai) have their origin in sensation by means of coincidence (periptosis) and analogy (analogia) and similarity (homoiotes) and 
combination (sunthesis), reason (logismos) too contributing something. (Trans. Bailey 1926)

In the next section (10.33) Diogenes introduces the Epicurean notion of a prolepsis, which we can take to be a species of epinoia even though the presentation in that part of Diogenes' text switches to use what looks very much like originally Stoic terminology (ennoia, katalepsis, doxa orthe). For the most part, we can leave aside for now the various serious and interesting questions we might ask about the Epicurean doctrine of prolepsis and notice just that the epinoiai in 10.32 , by implication, are a more general kind of mental item and are certainly not all to be thought of as criteria of truth. ${ }^{6}$ What we have in 10.32 , in that case, is a more general account of the process of forming thoughts and concepts from sense-impressions which lists various kinds of intermediary mechanisms by which sensations generate these epinoiai. The precise explanation is unfortunately rather obscure but evidently we are being offered a list of various kinds of operation that we perform on sense-impressions to generate thoughts and concepts. Most likely, these operations involve conceiving of certain relationships between the sense-impressions: some impressions are taken to be like one another either in simple qualitative terms or by being analogous to one another; some impressions are combined with others. That allows sense-impressions to be grouped in some way so as to combine and produce a composite epinoia.

What is not clear is whether these operations are consciously applied by some deliberate act of reasoning or whether they are operations we tend to perform unconsciously. It is plausible, however, to think that the degree of effort and deliberate thought will vary. Sometimes we think about the similarity between different perceptions or spend some time and effort fitting the evidence of many sense-impressions together and the process of generating epinoiai from our sense-impressions will be effortful and deliberate. Sometimes, by contrast, we do these things spontaneously. Indeed, the Epicurean texts sometimes describe in simple physical terms how a stream of eidola may generate the continuous and unified impression of a given external object simply because the stream of qualitatively similar eidola is continuous and also preserves the sumpatheia of the source object (Ep. Hdt. 49-50; cf. Epicurus, Nat. 2 PHerc. 1149/993 Col. 38 Leone). For example, in the notorious passage from Cicero's De natura deorum, 1.49 which purports to explain the way in which, according to the Epicureans, we humans come to form a notion (intellegentia) of divine blessed and eternal natures, some emphasis is

6. For recent accounts of Epicurean prolepsis see Morel 2008 and Tsouna 2016. Epinoia occurs also at Epicurus, Ep.Hdt. 45 in the phrase: 'the epinoia of the nature of what exists'

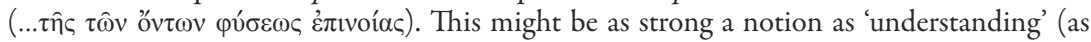
Bailey's translation has it) but is more likely to be a less restrictive description of the type of cognition involved (Hicks 1925, for example, translates epinoia as 'conception'). 
placed on the receipt of a series of images (this time not perceptual images, of course) that are connected through their similarity to one another. Also, the Epicureans suggest sometimes that the lasting effect on the perceiver's soul of such streams is what enables us to think of the original object even when it is not present since the relevant passages have been opened up to accommodate the finer intelligible eidola (e.g. Diogenes of Oinoanda, fr. 9 Smith).

The terms periptosis, analogia, homoiotes, and sunthesis also occur regularly in Philodemus' De Signis. There it seems that they refer to various ways in which we might use information we already possess to construct new beliefs and claims. For example, in the section beginning at Col. II.25 De Lacy, Philodemus relates various objections to the method of inference 'dia homoiotetos.' One of the candidate inferences is the following: we are justified in concluding that all humans are mortal provided we accept that all humans we have encountered are mortal and that the humans we have not encountered are similar to the ones we have encountered. Later (Col. XII.36ff. and XVI.1ff.) Philodemus returns to deal with some of the various objections to this method that are grounded, for example, on charges of question-begging or of inconsistency. He does this by pouring scorn generally on any reluctance to accept inferences based on clearly-perceived and uncontested similarities between observed members of the same species and then turning the tables on his opponents by arguing that their own preferred method is itself based on the method of inference by similarity. There are lots of interesting things we might say about this debate. However, for present purposes we should simply note that Philodemus' interest is principally in accounting for sign-inference as a more or less deliberate method of coming to a view about something non-evident (adelon). The intricacies of the various objections and reformulations of the ways in which such inferences are and are not reliable shows that often we will need to reason carefully and reflectively when moving from the primary evidence of our perceptions to any claims about non-evident matters. In that case, his use of the various intermediary tools between sense-impressions and epinoiai will to a large extent be concerned with such deliberate and self-conscious acts of reasoning. But we have seen enough, I think, to be confident that the Epicureans also thought that we sometimes come to form general conceptions through the repeated reception of similar appearances in a less self-conscious fashion. Indeed, Philodemus himself sometimes seems to be describing a process of that kind as when, for example, he says that it is important to encounter (the relevant term is periptosis) multiple instances which are varied but all of a kind (homogeneis kai poikiloi: XX.36) in order to form a conception of a given kind that includes only those properties which are inseparable 
and necessary. So, for instance, we meet many people who differ from one another in many ways, but recognise that they are all subject to disease and old age and hence reliably form the conception of humans as all mortal. This is something that we do without any conscious effort.

Some further help in understanding the notion of periptosis comes from Sextus once again. At $M$. 8.56-60, Sextus is some way into his large-scale inquiry into 'the true'. He pairs Plato and Democritus as both dismissing the truth of sense-impressions and offers the following argument against them:

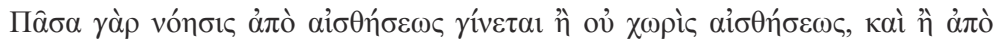

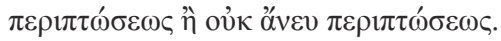

For every thought (noesis) occurs either owing to sensation or not apart from sensation, and either owing to periptosis or not without periptosis. (Sextus Empiricus, $M .8 .56$.)

The next sentence says that even our dreams cannot be detached from things that are known to us via periptosis. Bury and Bett both translate all the occurrences of periptosis here as 'experience', presumably having in mind the general sense of the word as being 'circumstance' or 'what befalls us'. So the idea is that all our thoughts can ultimately be traced back to something we have perceived or something we have encountered or which has befallen us. What comes next in Sextus' account is a range of ways in which we can begin with something experienced but think of something else and this range includes some familiar terms from Diogenes Laertius, 10.32, and adds some new ones. For example, by 'similarity' (homoiotes) we may see a picture of Socrates and come to think of Socrates himself. By 'increase' (parauxesis) or 'decrease' (meiosis) we might begin with the impression of an ordinary person and conceive of a giant or a pygmy. By 'combination' (episunthesis) we may come to the thought of a centaur from our experiences of a person and a horse.

The source for this part of Sextus' account is not named explicitly but it is certainly a source that he can easily oppose to the anti-empiricism he finds in Plato and Democritus. So it would not be a surprise if the Epicureans were involved, particularly since Epicurus is invoked by name just a little later at 8.63 where he too comes in for criticism from Sextus. Epicurean or not, here at 8.56-60 we have another version of the general idea found in Diogenes Laertius, 10.32: our sense-impressions may form the basis for thoughts and concepts that are not entirely provided by the sense-impressions alone. In various ways we can be put in mind of things other than those which we now perceive and have previously perceived. But in all these cases the sense-impressions form the basis for those thoughts.

We could press for more precision on each of these terms and there are of course important local interpretative questions that we might pursue about each of these texts and passages. But the overall point is relatively straight- 
forward. When at Diogenes Laertius, 10.32, we are told that 'reasoning also

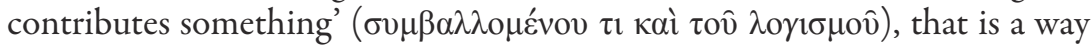
of generalising over all of the preceding ways in which we make inferences or expand upon the basic information provided by the senses. So the texts we have just surveyed all present an important element of the Epicureans' empiricist psychology and epistemology, namely the various ways in which we can extrapolate from, combine, compare, and manipulate the primary data we receive from sense-impressions in order to generate both general concepts and also concepts of non-perceptible things. Although the texts do not stress this aspect of the theory, it must be the case that at least some of the time these operations are carried out automatically or, as the Epicureans might put it, naturally. We know that this must be the case because that is certainly what must happen in the formation of prolepseis, whatever the other intricacies and difficulties of that aspect of Epicurean epistemology. And we can therefore presume that it may also happen to form non-veridical epinoiai. These epinoiai must be to blame for the opinion that sense-impressions can conflict. How?

One way to characterise the Epicureans' view is to say that, according to them, we humans often naturally take sense-impressions as evidence for opinions that are more general than the impressions themselves strictly warrant. We move-often without any conscious effort-from the veridical content of a sense impression ' $\mathrm{X}$ appears F' to the opinion that ' $\mathrm{X}$ is $\mathrm{F}$ '. And we often move from the veridical content of a group of sense-impressions to form opinions whose content is more general: 'this $\mathrm{X}$ appears $\mathrm{F}$, 'that $\mathrm{X}$ appears F'... to the opinion that 'Xs are F'. Now, this is usually a good and helpful thing and it may be that animals that are able to form beliefs in this way are likely to survive and thrive according to the Epicureans' account of natural selection. However this mechanism for the formation of beliefs on the basis of empirical input did arise, it must be what allows for the generation of general concepts or for inductive means of acquiring beliefs. For example, consider the way the Epicureans go about explaining how we are able to acquire general concepts of things via the repeated perception of objects of the same kind. Although the Epicureans' account of prolepseis is in many ways rather obscure, it seems to be more or less agreed that part of the role of these concepts is to allow us to form general notions of kinds of things in an empiricist fashion and that these general concepts in turn allow us to understand and categorise new items we encounter (see Diogenes Laertius, 10.33). Of course, these prolepseis are special insofar as they are held by the Epicureans to be another of the criteria of truth and so cannot be held in the least responsible for any cognitive errors to which we may be prone. Nonetheless, the Epicureans think it is important to insist upon the broad distinction between what are perceptions and what are opinions, with only 
the former being necessarily true. Any conflict that we may think we identify between perceptions must instead be a conflict either between a perception and an opinion (in which case the opinion should be rejected) or between two opinions. ${ }^{8}$

For the most part, it is a good thing that we generally extrapolate from our own experiences of a given object to assume that it will appear similarly to others since, for the most part, that is how things are and people are sufficiently similar that such assumptions are usually reliable. It helps us to negotiate the public world and to communicate with one another on the basis of shared assumptions about how things are and how they appear to others. But on occasion this can be misleading since we may sometimes be faced by situations such as that of the sweet-and-bitter-tasting wine or the straightand-bent oar that we will consider shortly. Sometimes we will have to think carefully in order not to form the false belief that there are cases of perceptual conflict. On those occasions we will need to be reminded by Epicurus of the important difference between perceptions and opinions and the specificity of each of our sense-impressions so as not to be led into the temptation of thinking any sense impression can be false.

In fact, it seems rather important to be reminded that we can pay more or less attention to the precise evidence that our senses provide since one of the Epicureans' tactics for discouraging the formation of the false belief that sense-impressions may conflict is precisely to point out the specific and special objects of each sense modality so as to underline how they do not in fact overlap in such a way as to be able to conflict. They similarly remind us that each impression from a single given sense modality is from a certain perspective and at a certain time and therefore its content is circumscribed so as to prevent it from conflicting even with a similar impression received a short time before or after. In short, they draw our attention to the precisely circumscribed content of each impression so as to make sure that we recognise the inferential moves required to go from the veridical content of a group of sense-impressions to any opinion we might form on the basis of the evidence they offer. Since each sense-impression is qualified in important ways then forming general opinions about some object or class of objects will always require some additional cognitive work. Provided we take care to notice in this way just how the members of a group of sense-impressions are similar to one another-something that might in fact require a significant

8. See also Reinhardt 2016 for an account of Lucretius' careful use of terms for 'seeing' and 'being seen' which encourages the correct appreciation of the distinction between an 'alogos' perceptual appearance and an opinion drawn from those appearances. 
amount of cognitive effort-then we may be able to form correct opinions and will be less likely to form the mistaken belief that the sense-impressions conflict. This may well lead us to be more circumspect in our otherwise casual formation of beliefs. Nevertheless, for the most part we go about our lives not needing constant reminders of this sort and not needing to expend any such deliberate cognitive effort in scrutinising the precise content of the sense-impressions we receive. For the most part, we happily engage these operations and combine and compare our impressions in order to generate reliable thoughts about the world.

One of the ways in which the Epicureans advise us to take care of the way in which we use the information provided by our sense-impressions is their repeated insistence that no sense-impression is able to convict any other of falsehood. This is noted in the basic texts that deal with the foundations of Epicurean empiricism and those texts are often rightly invoked in discussions of the Epicureans' treatment of various forms of scepticism. The insistence, therefore, on the distinctness of the objects of each sense-modality and also of the distinctness of each impression received by a single sense-modality is thus one way in which the Epicureans try to defuse the very possibility of conflict that is often the starting-point for sceptical attitudes. At DRN 4.478-99, for example, after listing various examples of cases which might undermine trust in the senses, Lucretius spends twenty lines emphasising how each sense-modality has its own separate power (nam sorsum cuique potestas | divisast: 489-90) and that each sense impression from the same sense must be granted equal credibility (aequa fides quoniam debebit semper haberi: 498$)$.

In short, these texts emphasise the message we extracted from our account of Sextus M. 7.206: that sense-impressions differ but cannot conflict. And so, before coming to a close, let us look briefly at two cases of apparent conflict and consider how the Epicureans explain them. First, take the case of an apparent conflict of appearances taken from an example apparently discussed in Epicurus' work Symposium, which we know about principally through the critical account of his view found in Plutarch's Adversus Colotem, $1109 \mathrm{E}$.f. ${ }^{10}$ (The Symposium, it seems, was written as a dialogue since Plutarch refers to a discussion between Polyaenus and Epicurus.) Reclining after dinner, we pass around a cup of wine. I drink the wine and I find it warming. You

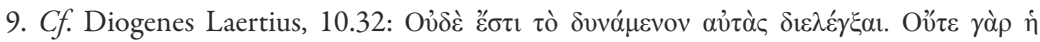

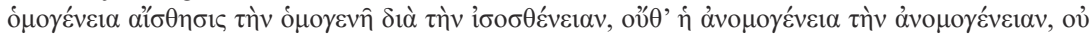

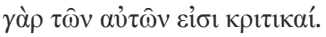

10. For discussion of this passage see Castagnoli 2013. 
drink the wine and tell me it chills you. Now, there are various things I might go on to conclude once I come to the view that you and I are having conflicting sense-impressions but what would lead me to the thought that the sense-impressions are conflicting in the first place? It must be because

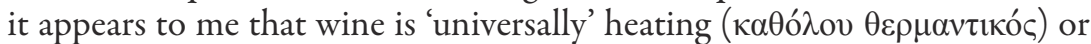
'universally' cooling and I am sure that you and I have drunk the same wine. But this appearance of a universal perceptible quality is in fact an opinion that I have come to hold, perhaps without any particular deliberation on the matter, perhaps because of my own repeated experience and perhaps from never before having encountered anyone quite like you. It's impossible to perceive something as 'universally' $\mathrm{F}$ since each perception reports only a single interaction between the subject and a source object. I would also, of course, be wrong to think that you must be somehow misperceiving the wine since that would imply that your perception is not true. So what should we instead conclude, according to Epicurus? Apparently, we should conclude not that wine is 'universally warming' but rather that a certain quantity of wine is warming for a nature of a certain kind and in a certain condition and is cooling for a nature of a different kind in a certain condition. It is worth remarking, of course, that this emphasis on the distinctness of each sense-impression by reference to the specific conditions of a particular act of perception also appears in various other competing epistemological accounts such as the developed form of relativism in Plato's Theaetetus which share with the Epicureans a desire to retain a kind of truth for each impressionrelative truth, loosely speaking, in the case of the Protagorean account-by removing the possibility of conflict. It is no surprise, in that case, to find that sources hostile to the Epicureans such as Plutarch will note this similarity and more or less accuse the Epicurean position as collapsing into a kind of relativism. But Epicurus' claim is not a concession to Protagorean-style relativism because he is ascribing a property - a complex dispositional property, perhaps-to the wine itself. When you and I taste it we react differently because we are different but we are both reacting to this particular quantity of wine and the nature that it has and that nature is independent of any act of perception. ${ }^{11}$

In the case of the warming and cooling wine in Epicurus' Symposium, the conflict was mistakenly assumed because it is not appreciated just how the state of the perceiver in part determines which aspects of the perceptible object are registered. So, the fault must be that on the basis of my experiences I have come to some expectation about how everyone will experience the wine; I have formed a false opinion about how the wine tastes universally

11. There is an extended defence of the reality of such properties in Polystratus' On the irrational contempt for common opinions, XXI.8-XXV.24 Indelli. See Indelli 1977, Indelli 1978; Warren 2002, p. 142-9. 
(katholou). Faced with evidence to the contrary of that expectation, then I am led to think that one of us must be mistaken when I should instead conclude that this difference between your experience and mine is not a conflict at all; it is instead precisely how we should react respectively to this quantity of wine of this kind given our respective current and differing circumstances. Since I am not carefully distinguishing as the Epicureans say I should between perceptions (even perceptions of one and the same object) and opinions about that object, then I may well take this to be a case of a conflict of appearances. And, we might add, I may fail to make that distinction between what is a perception and what an opinion in part because my misleading expectation about the properties of wine was formed gradually and as a result of my repeated experiences. I did not, in other words, make any clear and deliberate inference in this case that might make me conscious of this being a fallible and defeasible opinion rather than a simple direct appearance. A full understanding of the mechanism involved in the complex interaction between the properties of the wine and the states of respective perceivers should be able to mitigate the chances of my making a similar mistake in the future.

Here is another situation, rather different from the previous case. From repeated perceptions of oars we come to form the belief that oars are straight. We see oars propped up in boat sheds, we have noticed that they go into the water straight and emerge straight and so on. We form the belief in that case that oars are straight. And let us stipulate that this belief is true. ${ }^{12}$ But now some unhelpful person draws our attention to an oar that is partially submerged. We are asked to look at it and then run our hand along it. We notice that it looks bent but feels straight. Imagine further that we have not yet come to realise how refraction varies through media of different densities and we have not yet fully grasped Lucretius' insistence that the different sense-modalities are, strictly speaking, registering independent perceptual aspects of the world. Nevertheless, in this case we might be inclined to think that there is a conflict here, perhaps because as Sextus put it in at M. 7.206,

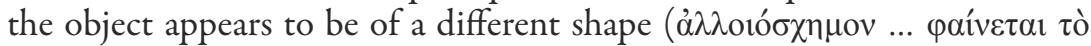
ілокв́́ $\mu \varepsilon v o v)$. We might form the belief that the oar appears both straight and bent. And, since there is a conflict here in which one side of the conflict must prevail—and since one side of the conflict: 'the oar is straight' accords with a long-standing belief-then we will be inclined to think that the visual appearance must be false. Our eyes must be deceiving us. This is a problem for many reasons, not the least of which is that our eyes have been responsible

12. We might even go so far as to allow us to have this as a preconception; it is not always clear what the full range of items is of which we can have such prolepseis. But let us for now just stipulate that we form a true standing belief about the nature of oars that includes their being straight. 
at least in part for the formation of the standing belief in the first place. It is also a problem if we begin to think that sometimes our perceptions are misleading or that sometimes our perceptions may conflict with one another.

In this case, Epicurus will try to combat the danger by again asking us to pay attention to the precise circumstances of the various perceptions we are comparing and contrasting. He will tell us to pay attention to the fact that the oar appears bent only when and for as long as it is partially submerged in the water. And then he will attempt an explanation for such appearances that is compatible with the robust opinion that we have that the oars are in fact always straight. In fact, given the way in which the air and water differently effect the way in which the eidola pass from the oar to our eyes (or, in our terms, the different refractive properties of these two media) then it is not merely possible for a straight oar also to appear bent; rather, that is precisely how a straight oar that is partially submerged in water ought to appear. A full understanding of the mechanism involved in vision should be able to mitigate the chances of my making a similar mistake in the future. Overall, the Epicureans are relying on the insistence that the combination of this explanation for the otherwise incongruous-seeming appearances with the general conception we have of how oars usually appear will be more convincing overall than any account that either tells us that sometimes our perceptions of the oars are false or some account that attempts to say that the oars change from being bent to being straight and then back again. Rather, we should notice that the impressions differ but do not conflict. And, furthermore, we can explain why a straight oar should present those differing appearances.

\section{6}

The upshot of this sketch of the Epicurean position is the following. The Epicureans want to promote a robustly empiricist stance and, in the face of long-standing sceptical doubts, insist that all our sense-impressions are true. What is more, they have a picture of human cognitive abilities that relies heavily on our naturally forming general concepts and acquiring general beliefs on the basis of our immediate sensory experiences. Those sensory experiences, given the mechanisms involved, provide us with various truths about the world around us and we naturally form beliefs based upon them. But those beliefs will often be about things that are beyond our experience: things that are non-evident either because they are universal claims while we have merely experienced finite examples of the relevant kind or because they are about things that are essentially non-evident.

The formation either of the belief that not all perceptions are true or the belief that sense-impressions conflict is a specific result of a general difficulty that besets the formation of all beliefs on the basis of true sense-impressions. It is important for the Epicureans to address such beliefs because their 
presence may actively prevent the positive and reliable use of true senseimpressions for forming true beliefs. But the Epicureans have a difficult task in balancing different aspects of their account. The more they emphasise the distinctness of the objects of each sense-modality or the distinctness of each sense-impression from the same sense-modality, the easier it will be for them to resist claims of inter-impression conflict and assure us that the belief that our sense-impressions conflict must be false. However, this emphasis on the distinctness of our impressions will put more pressure on another part of their account, namely the way in which we can nevertheless use these various very specific sense-impressions to form general beliefs; the distinctness of each impression, to put the matter succinctly, means that there is more cognitive work to be done once all the direct sensory evidence has been received: logismos will have to make a non-trivial contribution if we are going to move from specific sense-impressions to reliable general beliefs. And it is precisely in the formation of beliefs on the basis of our sense-impressions that falsehoods may begin to enter the picture. On the other hand, the richer the initial content of initial true sense-impressions and the less work there is left for logismos to form general beliefs then the more likely it is that the Epicureans will find it hard to resist and explain away purported cases of perceptual conflict.

It may be the case, but this is just a speculation, that Epicurus began with a rather simple and optimistic view that we are indeed for the most part rather successful at forming reliable beliefs on the basis of our sense-perceptions without the need of much attention and caution. The sheer fact that we are generally successful at navigating the world and at communicating with one another might be offered as evidence in support of this view. But increasing and persistent sceptical attacks on this optimistic view forced Epicurus to deal head-on with the dangerous possibility of conflicts between sense-impressions. The possibility that our sense-impressions might conflict with one another has to be denied by the Epicureans because that possibility threatens the foundations of their empiricist epistemology. As Epicurus himself admits at Ep. Hdt. 51, any cognitive errors to which we are prone must be due to some 'motion within us' different from the simple and alogoi mechanisms of perception. But that reply entailed two additional moves on the part of the Epicureans. First, it required them to make clear the restricted nature of any given sense-impression so as to insulate each one from potential conflict with any other sense-impression and leave them all with equal credibility. And, second, it entailed their explicitly accepting a critical perspective on the beliefs that we may form on the basis of our sense-perceptions. Both of those, however, had to be presented in such a way as to leave intact enough of Epicurus' initial starting optimism about our ability to form reliable general beliefs on the basis of our true sense-impressions. So here is the problem: 
the more distinct each sense-impression must be in order to ensure a lack of conflict, the more work there is for reason to do in generating useful general beliefs from these sense-impressions. But the greater the distance, so to speak, between the information provided by sense-impressions and the general claims we form as beliefs, the greater the chance for error.

The particular false belief that sense-impressions conflict, like all other false beliefs, is also the result of a failure to recognise just what information our true sense-impressions convey. We will think that sense-impressions conflict if we mistake what is a belief for a sense-impression. So this particular false belief is also a good example of how a failure to distinguish between what our sense-impressions convey and what is already a belief can lead to further and more damaging false beliefs by hampering our chances of making positive epistemological progress and encouraging unwarranted scepticism about our sense-impressions. 


\section{BIBLIOGRAPHY}

Allen, J. 2001 : Inference from Signs: Ancient Debates about the Nature of Evidence, Oxford, 2001.

BAILey, C. 1926 (éd.) : Epicurus, The Extant Remains, Oxford, 1926.

Bett, R. 2005 (éd.) : Sextus Empiricus, Against the Logicians, Cambridge, 2005 (Cambridge Texts in the History of Philosophy).

Burnyeat, M. F. 1981 : «Conflicting appearances », Proceedings of the British Academy [1979], 65 (1981), p. 69-111.

URL : https://www.thebritishacademy.ac.uk/pubs/proc/files/65p069.pdf

Bury, R. G. 1935 (trad.) : Sextus Empiricus II. Against the Logicians, Harvard, 1935 (Loeb Classical Library, 291).

Castagnoli, L. 2013 : «Democritus and Epicurus on sensible qualities in Plutarch's Against Colotes 3-9 », Aitia. Regards sur la culture hellénistique au $X X I^{e}$ siècle [on line], 3 (2013), mis en ligne le 25 Novembre 2013, consulté le 14 Novembre 2016.

URL : http://aitia.revues.org/622.

De Lacy, P. \& E. A. De Lacy 1978 (éd.) : Philodemus, On Methods of Inference, Napoli, 1978 (La scuola di Epicuro, 1).

Everson, S. 1990 : « Epicurus on the truth of the senses », dans S. Everson (éd.) Epistemology, Cambridge, 1990, p. 161-183.

Gigante, M. 1981 : Scetticismo e epicureismo, Napoli, 1981 (Elenchos, 4).

Hicks, R. D. 1925 (trad.) : Diogenes Laertius, Lives and Opinions of Eminent Philosophers (2 vol.), Harvard, 1925 (Loeb Classical Library, 184-185).

IndelLi, G. 1977 : « Polistrato contro gli scettici », Cronache Ercolanesi, 7 (1977), p. 85-95.

InDELLI, G. 1978 (éd.) : Polistrato, Sul disprezzo irrazionale delle opinioni popolari, Napoli, 1978 (La scuola di Epicuro, 2).

LÉVY, C. 1997 : «Lucrèce avait-il lu Énésidème ? » dans K. A. Algra, H. M. Koenen, P. H. Schrijvers et al. (éd.), Lucretius and his Intellectual Background, Amsterdam, 1997, p. 115-124 (Koninklijke Nederlandse Akademie van Wetenschappen / Afdeling Letterkunde, 172).

Morel, P.-M. 2008 : « Method and evidence : on Epicurean preconception », Proceedings of the Boston Area Colloquium in Ancient Philosophy [2007], 23 (2008), p. 25-48.

REINHARDT, T. 2016 : « To see and be seen : on vision and perception in Lucretius and Cicero », dans G. D. Williams \& K. Volk (éd.), Roman Reflections : Studies in Latin Philosophy, Oxford, 2016, p. 63-90.

Schrijvers, P. H. 1992 : « Philosophie et paraphrase : Lucrèce et les sceptiques », dans La Langue latine, langue de la philosophie, Rome, 1992 (Collection de l'École française de Rome, 161), p. 125-147.

Scotт, D. 1989 : «Epicurean Illusions », The Classical Quarterly, 39 (1989), p. 360-374.

Sedley, D. N. 1992 : « Sextus Empiricus and the Atomist Criteria of Truth », Elenchos, 13 (1992), p. 19-56.

STRIKER, G. 1977 : « Epicurus on the Truth of All Sense-impressions », Archiv fur Geschichte der Philosophie, 59 (1977), p. 125-142 (= Essays on Hellenistic Epistemology and Ethics, Cambridge, 1996, p. 77-91). 
TAYlor, C. C. W. 1980 : « All Perceptions are True», dans M. Schofield, M. Burnyeat, J. Barnes (éd.), Doubt and Dogmatism, Oxford, p. 105-124.

Tsouna, V.2016: «Epicurean preconceptions », Phronesis, 61 (2016), p. 160-221. Warren, J. 2002 : Epicurus and Democritean Ethics : An Archaeology of Ataraxia, Cambridge, 2002. 